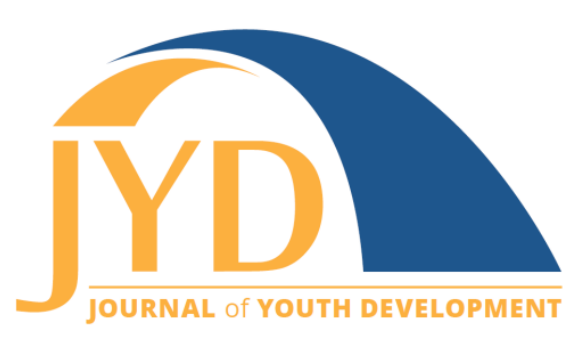

http://jyd.pitt.edu/ | Vol. 15 Issue 4 DOI 10.5195/jyd.2020.881 | ISSN 2325-4017 (online)

\title{
Determinants of Motivation for Mentoring Among Adults Volunteering to Mentor Youth
}

\author{
Miriam Miranda-Díaz \\ Portland State University \\ mirandam@pdx.edu
}

Hyuny Clark-Shim

Portland State University

h.clarkshim@pdx.edu

Thomas E. Keller

Portland State University

kellert@pdx.edu

Renée Spencer

Boston University

rspenc@bu.edu

\begin{abstract}
Most youth mentoring programs rely on volunteers to serve as mentors to youth. This study investigates factors associated with motivations for volunteering in this capacity, specifically altruistic and self-oriented reasons for becoming a mentor. Because adults who volunteer as mentors and youth mentees typically come from different socio-cultural backgrounds, the study examines demographic characteristics associated with these different motivations. In addition, the study addresses the empathy-altruism hypothesis suggesting that individuals with higher levels of empathy exhibit greater altruistic tendencies. For this analysis, the focus is on ethnocultural empathy and its association with volunteer motivations. The sample consisted of 1,000 volunteers who applied to mentor in 4 agencies affiliated with a national mentoring organization. The results indicated that mentors reporting higher levels of ethnocultural empathy were more likely to endorse altruistic motivations for volunteering. Younger volunteers, female volunteers, and volunteers of color reported higher levels of self-oriented motivations for volunteering. Female mentors, in general, reported higher levels of altruistic motivations for volunteering. Altruism and empathy, particularly the ability to connect with youth across cultural differences, are considered important mentor attributes conducive to healthy mentoring relationships. The implications of these findings for research and practice are discussed.
\end{abstract}

Key words: youth mentoring, ethnocultural empathy, volunteer motivation

(cc) EY New articles in this journal are licensed under a Creative Commons Attribution 4.0 License. This journal is published by the University Library System, University of Pittsburgh and is cosponsored by the University of Pittsburgh Press. The Journal of Youth Development is the official peer-reviewed publication of the National Association of Extension 4-H Youth Development Professionals and the National AfterSchool Association. 


\section{Volunteer Motivation for Mentoring}

Many people in the United States volunteer their time in a variety of volunteer roles. Recent figures indicate that approximately 62.6 million individuals ( $25.3 \%$ of total U.S. population) served as volunteers through an organization (Bureau of Labor Statistics, U.S. Department of Labor [BLS], 2016). Demographic factors associated with a greater likelihood of volunteer service are gender (female), race (white), and age (35 to 44 years; BLS, 2016). Roughly a quarter of volunteers endorsed their main volunteer organization as "educational or youth service related" (BLS, 2016, p. 2). Mentoring is a popular role for many people who wish to volunteer their time to form supportive relationships with youth and contribute to positive youth development (Lerner et al., 2014). Mentors act in "a non-professional helping capacity to provide relationship-based support that benefits one or more areas of the mentee's development" (MENTOR/The National Mentoring Partnership, 2015, p. 9). An estimated 4.5 million youth are in a formal mentoring relationship (Bruce \& Bridgeland, 2014).

There have been several investigations into the motivations that prompt individuals to volunteer. Clary et al. (1998) explained volunteer motivation through a functionalist approach, which assumes people perform their volunteer work in the service of different psychological functions. The functions served through volunteerism may include self-oriented growth (personal and/or career oriented) or the goal to enhance or establish relationships. Volunteerism also can serve as a protective function from unpleasant or negative feelings such as guilt, more specifically "reducing guilt over being more fortunate than others and to address one's own personal problems" (Clary et al., 1998, p. 1518). Volunteerism also offers the opportunity to "express values related to altruistic and humanitarian concerns for others" (Clary et al., 1998, p. 1517). Several other authors have formulated a connection between altruism and volunteerism (e.g., Haski-Leventhal, 2009; Hwang et al., 2005).

Volunteer motivations have been associated with specific types of opportunities and tasks that volunteers may choose to perform (Clary \& Orensteing, 1991; Coursey et al., 2011). Volunteer motivations also predict volunteers' satisfaction, performance, and commitment to their volunteer role in the setting where they choose to volunteer (Clary \& Orenstein, 1991; Cornelis et al., 2013). For example, Cornelis and colleagues (2013) found in their study that both selfand other-oriented motives (e.g., altruism) were associated with a volunteer's overall satisfaction with their volunteer experience as well as extra-role behavior in which volunteers engage in helping behaviors over and above those expected as part of their role or assigned tasks. Volunteer motives also can be a predictor of volunteers' success in performing altruistic activities (Clary \& Orenstein, 1991). Furthermore, when compared to volunteers who completed 


\section{Volunteer Motivation for Mentoring}

their commitment or who were screened out by the agency, volunteers who prematurely end their volunteer commitment have lower levels of altruistic motivation (Clary \& Orenstein, 1991). Consequently, if agencies are interested in recruiting volunteers who will be effective and committed to their volunteer role, it is important to examine volunteers' skills and motivations to understand if and how much help a volunteer may choose to give, and also how effective the help might actually be (Clary \& Orenstein, 1991).

Motivations for volunteering have been linked to certain individual characteristics or attributes, including personality and social and personal demographics, such as age and life stages. For example, younger volunteers may choose to engage in volunteerism to develop "their own human capital" (Sherman \& Shavit, 2012, p. 1376). Furthermore, Clary and colleagues (1996) used demographics for assessing different motivations for volunteering and concluded that there were differences amongst groups. For example, when compared to their counterparts, volunteers of color (who identified as Black) and female volunteers were more likely to endorse most of the different domains from the Volunteer Functions Inventory (career, social, understanding, protective, enhancement, values) as being important (Clary et al.,1996). These findings suggest that gender and race/ethnicity are factors in predicting the different types of volunteer motivations.

A theory that has been proposed to explain human altruistic motivation and behavior is the empathy-altruism hypothesis. To have empathy and empathic concern implies that this is often in response to the suffering or need of someone else. It is important to underscore that empathic concern is emotionally charged and carries a range of mix of emotions (e.g., compassion, distress, concern, sadness, and tenderness; Batson et al., 2015). Empathy induced by the perceived suffering or need of someone else is most likely to lead to altruistic motivation (especially when driven by empathic concern; Batson et al., 2015). The capacity to feel a sense of concern (empathic concern) for the welfare of others evokes a sense of "altruistic motivationa motivational state with the ultimate goal of reducing that need" (Batson et al., 2015, p. 1). Batson et al. (2015) conducted an extensive review of the literature on the empathy-altruism hypothesis and concluded that there is evidence suggesting that humans do have the ability to have altruism that is generated by empathy. However, based on their review of theory and research, they also caution on the implications of the empathy-altruism hypothesis, stating that the implications of altruism are mixed, such that altruism can be both beneficial and in certain circumstances detrimental. 


\section{Volunteer Motivation for Mentoring}

Mentoring programs serve a great number of youth who are from communities of color and/or economically disadvantaged, while the majority of volunteer mentors are of the predominantly White culture (Garringer et al., 2017; Raposa et al., 2017). Consequently, there is strong interest in exploring how race/ethnicity and culture affect the mentoring relationship (Sánchez et al., 2014). However, few studies have explored how attitudes and beliefs on race/ethnicity factor in the mentoring field. In one study, Spencer and colleagues (2011) found that some parents of mentees reported not feeling entirely comfortable with their child having a mentor with different demographic characteristics from their own (specifically race/ethnicity and socioeconomic status), because the socio-cultural differences sometimes created tensions.

One way to begin to understand how race/ethnicity factors in mentoring relationships is by examining mentors' ethnocultural empathy and how this form of empathy is related to volunteer mentors' motivations for volunteering. Ethnocultural empathy may be defined differently depending on the profession, and it has been compared with other terms such as "cultural competence, culture empathy and trans-cultural empathy" (Rasoal et al. 2011, p.6). Rasoal et al. (2011) attempted to provide a common definition by stating that ethnocultural empathy is "an interpersonal phenomenon where the two persons care as well as think and feel . . . feeling, understanding, and caring about what someone from another culture feels, understands, and cares about" (p. 8). Wang et al. (2003) conceptualized ethnocultural empathy as having empathy toward individuals of a different racial and/or ethnic background and noted that this form of empathy is driven by four main pillars: empathic feeling and expression, empathic perspective taking, acceptance of cultural differences, and empathic awareness.

Some investigators have examined how mentor ethnocultural empathy relates to youth outcomes in youth mentoring relationships. In a study conducted by Peifer and colleagues (2016) a mentor's ethnocultural empathy was influential in their mentee's ethnic identity exploration, particularly for mentees of color. Moreover, in cross-race matches, mentor ethnocultural empathy was a strong indicator of youth feeling emotionally connected to the relationship (Leyton-Armakan et al., 2012).

Although the studies just described examine ethnocultural empathy in youth-mentoring relationships, the focus is on youth outcomes. In the current study, the emphasis is on examining whether mentor ethnocultural empathy is associated with specific motivations for becoming a volunteer mentor. Why do volunteers choose to become mentors? What motivates them to assume this role? What factors influence their motivation? Understanding volunteer 


\section{Volunteer Motivation for Mentoring}

motivation is essential if programs are interested in recruiting and retaining mentors who will be able to form strong bonds with mentees (Stukas et al., 2014). Since mentors and youth often come from different socio-cultural backgrounds, volunteer mentors' skills and their ability to appreciate those differences are crucial to build and maintain a strong relationship. Empathy and altruism have been identified as important skills and abilities that foster perspective-taking which, in turn, can promote healthy mentor-mentee relationships (Liang et al., 2002; Stukas et al., 2014). These may be driving forces for people to volunteer.

The limited research on mentors' attitudes and beliefs about volunteering leaves fruitful ground for further exploration (Stukas et al., 2014). The current study investigates how certain demographic characteristics and volunteer/mentor ethnocultural empathy are related to specific motivations for becoming a volunteer mentor. Here, we are specifically interested in examining if ethnocultural empathy is a factor in predicting altruism (similar to the empathy-altruism hypothesis). Our primary research question is: What factors are related to specific motivations for becoming a volunteer mentor? Specifically, we focus on two motivations: altruistic and selforiented motivations. As noted, altruism is conceptualized as humanitarian or selfless acts of giving service to others including volunteer work such as mentoring; conversely, self-oriented motivation is to serve the purpose of personal and/or career growth with benefits for the mentor. Given that ethnocultural empathy is about having empathy toward a person from a different background than one's own (Wang et al., 2003), we hypothesize a positive relationship between ethnocultural empathy and altruistic motivation for becoming a volunteer mentor.

\section{Method}

The current study uses baseline data from a larger mixed-method study examining mentoring relationships over time (Keller \& Spencer, 2017). Study recruitment and baseline data collection began in the fall of 2013 and formally ended in the spring of 2015. Participants were recruited from four agencies affiliated with a national mentoring organization. The four sites were located in major cities in Oregon, California, Colorado, and Arizona. During the enrollment period, staff members at each agency invited all mentors applying to their respective programs to participate in the study. When mentors expressed interest in participating in the study and provided informed consent, the agency created a participant record in a secure online REDCap database (Harris et al., 2009) shared with the research team. Using the contact information in this record, the research team sent an email to the participant with a link to an online survey administered using Qualtrics (https://www.qualtrics.com). Participants completed a baseline 


\section{Volunteer Motivation for Mentoring}

survey prior to being matched with their mentee and starting the mentoring relationship. Participants did not receive any incentives for completing the baseline survey but were informed they would be eligible for one at the time of the follow-up survey. The university Institutional Review Board granted approval to conduct this research involving human subjects (Keller \& Spencer, 2017). All data were analyzed using SPSS (Version 25.0).

\section{Participant Description}

A total of 1,286 volunteers applying to become a mentor were approached to take part in the study. Of these mentors, $1,127(87.6 \%)$ consented to be in the study. Among these consented mentors, $1,000(88.7 \%)$ completed the baseline survey. Based on their reports, volunteer mentors were 18 to 76 years old $(M=31.84, S D=11.12)$. There were more female mentors $(61.2 \%)$ than male mentors. The majority of volunteers identified as European American/White (70.2\%), followed by 7.7\% Latina/o, 5.1\% Asian American/Asians, 4.2\% African

American/Black, and $12.7 \%$ multiracial/other. It was most common for volunteer mentors to be single (54.2\%), although $22.2 \%$ were married, $12.4 \%$ were living with a partner, $9.4 \%$ were divorced, $1.1 \%$ were married but separated, and .7\% were widowed. The majority of mentors had at least a bachelor's degree (71.6\%) and reported a household income above $\$ 50,000$ (58.9\%). The sample mainly consisted of participants who were "employed full-time" (69.5\%).

\section{Measures}

The demographic variables in the analysis are age, gender, and race/ethnicity. The variables for race and ethnicity were collapsed into two groups for further analyses: European American/White volunteers and volunteers of color.

The Scale of Ethnocultural Empathy (SEE; Wang et al., 2003) measures a person's level of empathy toward individuals of a different racial and/or ethnic background. Higher scores indicate a higher level of ethnocultural empathy. Items included statements such as "I can relate to the frustration that some people feel about having fewer opportunities due to their racial or ethnic background. "The negatively phrased items include "I feel irritated when people of different racial or ethnic backgrounds speak their language around me." Responses on a 6point Likert scale ranged from "strongly disagree" to "strongly agree." The scale had good internal consistency in the current sample (Cronbach's $a=.79$ ). A composite mean score was calculated for all cases with limited item-level missing data (see Newman, 2014; Parent, 2013). 


\section{Volunteer Motivation for Mentoring}

The Volunteer Motives Scale (Davis et al., 2003) was developed by drawing from several earlier measures assessing volunteer motivation (e.g., Clary \& Orenstein, 1991; Cnaan \& GoldbergGlen, 1991; Omoto \& Snyder, 1995). The measure is composed of 24 items and includes two main factors: self-oriented and altruistic motivations. Self-oriented motivation indicates volunteering for the purpose of personal and/or career growth or benefits. Self-oriented motivation was measured with 18 items (Cronbach's a =.94). Example items for the selforiented motivation for volunteering include statements such as "To help build my resume." Altruistic motivation indicates volunteering based on humanitarian or selfless acts of giving service to others. Altruistic motivation was measured with six items (Cronbach's a $=.87$ ). Example items for altruistic motivation include statements such as "To give something back to the community." All the responses were based on a 7-point Likert scale and ranged from "extremely unimportant" to "extremely important." A composite mean score was calculated for all cases with limited item-level missing data (see Newman, 2014; Parent, 2013).

\section{Analysis}

Preliminary analyses involved examination of descriptive statistics for all variables and bivariate correlations among volunteer mentors' ethnocultural empathy, altruistic and self-oriented motivations for volunteering. Multiple regression analyses were conducted with each motive for becoming a volunteer mentor as a separate dependent variable. In the regression analyses, independent variables were volunteer mentor demographics (age, gender, and race/ethnicity) and ethnocultural empathy.

\section{Results}

Correlations among volunteer mentors' ethnocultural empathy, altruistic, and self-oriented motivations for volunteering are presented in Table 1. Ethnocultural empathy was associated with altruistic motivation but not self-oriented motivation. 
Journal of Youth Development | http://jyd.pitt.edu/ | Vol. 15 Issue 4 DOI 10.5195/jyd.2020.881

Table 1. Bivariate Correlations Between Ethnocultural Empathy and Volunteer Motivations

\begin{tabular}{|l|c|c|c|}
\hline & 1 & 2 & 3 \\
\hline 1. Ethnocultural empathy & - & & \\
\hline 2. Altruistic motivation & $.18^{* *}$ & - & \\
\hline 3. Self-oriented motivation & .03 & $.42^{* *}$ & - \\
\hline Respondents $(M)$ & 833 & 975 & 974 \\
\hline Mean $(S D)$ & $4.62(.64)$ & $5.92(.95)$ & $4.37(1.06)$ \\
\hline
\end{tabular}

$* p<.05, * * p<.01$

Results from multiple regression analyses conducted to examine factors associated with altruistic and self-oriented motivations are shown in Table 2.

Table 2. Multiple Regression Models

\begin{tabular}{|c|c|c|c|c|c|c|c|c|}
\hline & \multicolumn{4}{|c|}{ Altruistic motivation } & \multicolumn{4}{|c|}{ Self-oriented motivation } \\
\hline & $\boldsymbol{\beta}$ & $t$ & \multicolumn{2}{|c|}{$p$-value } & $\boldsymbol{\beta}$ & $t$ & \multicolumn{2}{|c|}{ p-value } \\
\hline Age & -.01 & -.36 & \multicolumn{2}{|l|}{ NS } & -.20 & -5.79 & \multicolumn{2}{|c|}{$<.001$} \\
\hline Gender & -.11 & -3.07 & \multicolumn{2}{|c|}{$<.01$} & -.15 & -4.39 & \multicolumn{2}{|c|}{$<.001$} \\
\hline Race/ethnicity & -.02 & -.46 & \multicolumn{2}{|c|}{ NS } & .12 & 3.39 & \multicolumn{2}{|c|}{$<.01$} \\
\hline Ethnocultural empathy & .18 & 5.01 & \multicolumn{2}{|c|}{$<.001$} & -.04 & -.98 & \multicolumn{2}{|l|}{ NS } \\
\hline \multirow[t]{2}{*}{ Overall model } & $F$ & $d f$ & $p$-value & $R^{2}$ & $F$ & $d f$ & $p$-value & $R^{2}$ \\
\hline & 10.08 & 4,823 & $<.001$ & .05 & 18.40 & 4,822 & $<.001$ & .08 \\
\hline
\end{tabular}




\section{Volunteer Motivation for Mentoring}

The first regression analysis examined how volunteer mentor demographics (age, gender, and race/ethnicity) and ethnocultural empathy were associated with altruistic motivation for volunteering. Ethnocultural empathy was a statistically significant predictor for altruistic motivation for volunteering. In general, mentors with higher levels of ethnocultural empathy exhibit higher levels of altruistic motivation for volunteering. Volunteer mentors' gender also was a statistically significant predictor for altruistic motivation for volunteering. In general, female mentors are more likely to endorse altruistic motivation for volunteering than male mentors. Volunteer age and race/ethnicity were not associated with altruistic motivation.

The second regression analysis examined how volunteer mentor demographics (age, gender, and race/ethnicity) and ethnocultural empathy were related to self-oriented motivation for volunteering. Volunteer mentors' age was a statistically significant predictor for self-oriented motivation for volunteering. In general, younger mentors are more likely to endorse selforiented motivation for volunteering than older mentors. Volunteer mentors' gender was also a significant predictor for self-oriented motivation for volunteering. Female mentors are overall more likely to endorse self-oriented motivation for volunteering than male mentors. Volunteer mentors' race/ethnicity was also a significant predictor for self-oriented motivation for volunteering. Mentors of color exhibit higher levels of self-oriented motivation for volunteering. However, volunteer mentors' ethnocultural empathy was not a statistically significant predictor for self-oriented motivation for volunteering.

\section{Discussion}

This study sought to expand our understanding of motivations for volunteering as a mentor by examining associations with volunteer characteristics and attitudes towards different cultural groups. Because adult volunteer mentors and youth mentees tend to come from different sociocultural backgrounds, it is important for agencies to understand what factors may influence volunteer motivations not only for developing recruitment strategies, but also providing needed support for mentors and mentees to navigate their differences and build and maintain a supportive relationship between them. Additionally, agencies that are interested in recruiting volunteer mentors who will be more satisfied with their volunteer experience and willing to perform helping behaviors beyond the expectations of their role, should consider examining volunteer motivations and matching these motivations to the volunteer role (Cornelis et al., 2013). 


\section{Volunteer Motivation for Mentoring}

The current study found that volunteer mentors' demographic characteristics and ethnocultural empathy were related to their motivations for volunteering. Mentors who reported higher levels of ethnocultural empathy tend to endorse higher levels of altruistic motivations for volunteering. As previously noted, ethnocultural empathy is conceptualized as having "empathy toward people of racial and ethnic backgrounds different from one's own" (Wang et al., 2003, p. 221) or "as an interpersonal phenomenon where the two persons care as well as think and feel . . . feeling, understanding, and caring about what someone from another culture feels, understands, and cares about" (Rasoal et al., 2011, p. 8). Altruistic motivation is about doing things for the benefit of humanity, including youth and communities. Consequently, consistent with the empathy-altruism hypothesis, the connection can be made between ethnocultural empathy and the level of importance in enhancing the quality of life of the mentee (altruistic motivation).

However, it is important to note that most volunteer mentors in this study reported relatively high levels of ethnocultural empathy and altruism. Unlike natural mentors (e.g., teachers, counselors, and relatives), who by the nature of their jobs or familial ties to a youth often fulfill certain mentoring responsibilities, all of the mentors in the current sample are making an intentional choice about becoming a formal mentor, and fostering a relationship with a mentee with whom they might not have ties (Keller, 2007). Thus, by virtue of choosing to become a formal mentor, it is possible that these mentors possess strong motivations for becoming a mentor, have a basic understanding of the type of youth served by the mentoring program, and have empathy towards youth who are often disadvantaged and/or of an ethnic-racial minority group.

With respect to the demographic variables, female mentors in general reported higher levels of both altruistic and self-oriented motivations for volunteering. Although males in the current study reported relatively high altruistic and self-oriented motivation, they did not endorse these motivations to the same degree as did females. This is an interesting phenomenon because despite seeking to become a formal mentor, which includes giving back to the community and establishing a relationship with a mentee, male mentors generally reported altruistic motivation as less important. What could potentially be motivating males to become volunteer mentors? Although this question necessitates further research, a potential explanation could be social pressure. Because more females tend to volunteer as mentors, some programs place a greater emphasis on recruiting male mentors to address the waiting lists for boys needing mentors. Consequently, it may be that males feel more external pressure from members within their 


\section{Volunteer Motivation for Mentoring}

social network (e.g., peers, community, significant other) to become volunteers/mentors (Stukas et al., 2014). Another possibility stems from research about gender differences in expectations for mentoring, which has indicated that males tend to expect to have fun in their relationships and may enter into mentoring focused on this aspect of the relationship (Spencer et al., 2018). Agencies may want to consider the messaging in their recruitment efforts and/or tailor the messaging addressing how the volunteer opportunity may meet the motivations of prospective volunteers, particularly if they wish to increase their volunteer pool or target specific groups of volunteers (Dolnicar \& Randle, 2007; Cornelis et al., 2013; Coursey et al., 2011). In this case, youth mentoring agencies that traditionally pair mentors and mentees based on gender should consider the motivations of prospective male mentors and align these motivations with their marketing efforts, especially if they wish to address the long wait list of young men needing male mentors in their programs.

Mentors of color generally endorsed higher levels of self-oriented motivation for volunteering. As noted, the majority of volunteers in formal mentoring programs tend to be European American/White with relatively high SES which is consistent with the current study's findings. However, not all mentors would fit into this typical profile. Thus, considering that there was a significant association between race/ethnicity and self-oriented motivation, it is uncertain if these mentors (who are of an ethnic-racial minority group) potentially belong to other nondominant groups (e.g., less economically privileged, and lower levels of education), and if these moderate the relationship between race and self-oriented motivation. In their study, Hwang et al. (2005) concluded that volunteers who were more disadvantaged, particularly in education and socioeconomic status potentially viewed volunteerism as an important outlet to enhance their skills and abilities and have access to opportunities and experiences that, in turn, "prove useful for personal betterment or advancement" (p. 399). However, these may not be the only motives encouraging volunteers of color to become volunteer mentors. A study investigating the motivations of ethnic-minority volunteers in programs for underserved youth reported motivations reflected in statements such as: "to create a sense of family" and to "help kids reconnect with their culture" (Silverberg et al., 2003, p. 59). These findings bring light to a different set of volunteer motivations that agencies should further explore throughout their volunteer recruitment, training, and retention processes, and perhaps incorporate appropriate practices that match these motivations, particularly because examining the motivations of volunteers of color has been historically under-investigated (Silverberg et al., 2003). It is important to underscore that being more inclusive of volunteers from communities of color and diversifying the pool of volunteers will bring richness to youth programs and will broaden 


\section{Volunteer Motivation for Mentoring}

practitioners' and researchers' understanding of the different motivations for volunteers of color (Silverberg et al., 2003). This is especially true for programs (including youth mentoring programs) that wish to have more representation of racial-ethnic minority mentors whose racial-ethnic and cultural background is similar to that of program youth. Further examination on how personal and social demographics predict different motivations for becoming a volunteer is warranted.

Age was associated with self-oriented motivation. In the current sample, the average age was 32 years-old, and it is possible that in their 30s and beyond, mentors have completed their educational studies and have some form of work experience or have an established career. Thus, they may not volunteer due to self-oriented reasons. However, we can only surmise about these possibilities, particularly because age was not a significant predictor in altruistic motivation. Prior research suggests that older volunteers, particularly volunteers who are retired or approaching retirement tend to engage in volunteer work and/or replace paid work with volunteer work (Sherman \& Shavit, 2012).

There are some limitations to the current study. The mentors in this study were assessed prior to being matched with a mentee and were still seeking to become mentors, which may have generated a bias toward putting responses into a favorable light (i.e., social desirability) while still under consideration by the agency. The second limitation of this study is the somewhat homogeneous sample as it relates to gender and race/ethnicity. However, the composition of this sample reflects the distribution of volunteer mentors more generally (Raposa et al, 2017). Another limitation of the current study is the cross-sectional design of the study, in which the direction of causality for the attitudinal predictors cannot be definitely established.

It is important for mentoring researchers and program practitioners to understand what attitudes and beliefs mentors bring to the mentoring relationship, particularly if it involves working with a vulnerable population. Further, it is important to underscore that individuals can have a wide range of motivations for volunteering, and these motivations are sometimes fluid and complex (Chacon et al., 2007; Stukas et al., 2014). Therefore, researchers as well as program practitioners should consider assessing motives throughout the mentoring relationship as this can bring light to the status and/or focus of the mentoring relationship from the mentor's perspective, which will ultimately impact the mentee's experience. Both altruism and ethnocultural empathy are considered favorable attributes for volunteer mentors, and the current findings suggest that these factors overlap to a certain extent. Programs wishing to 
Journal of Youth Development | http://jyd.pitt.edu/ | Vol. 15 Issue 4 DOI 10.5195/jyd.2020.881

Volunteer Motivation for Mentoring

have mentors with more altruistic motivation could seek out volunteers with higher levels of ethnocultural empathy.

\section{Acknowledgements}

This project was supported by Grant \#2012-MU-FX-0001 awarded to Thomas Keller and Renée Spencer by the Office of Juvenile Justice and Delinquency Prevention, Office of Justice Programs, U.S. Department of Justice. The opinions, findings, and conclusions or recommendations expressed are those of the authors and do not necessarily reflect those of the Department of Justice. The authors are grateful to our partner program sites who were excellent collaborators, and to the volunteers who agreed to participate in the study.

\section{References}

Batson, C. D., Lishner, D. A., \& Stocks, E. L. (2015). The empathy-altruism hypothesis. The Oxford handbook of prosocial behavior. 259-281. https://doi.org/10.1093/oxfordhb/9780195399813.013.023

Bruce, M., \& Bridgeland, J. (2014). The mentoring effect: Young people's perspectives on the outcomes and availability of mentoring. Civic Enterprise with Hart Research Associates for MENTOR: The National Mentoring Partnership. http://www.mentoring.org/images/uploads/Report TheMentoringEffect.pdf

Bureau of Labor Statistics, U.S. Department of Labor. (2016). Volunteering in the United States 2015. https://www.bls.gov/news. release/volun.nr0.htm

Chacon, F., Vecina, M. L., \& Davila, M. C. (2007). The three-stage model of volunteers' duration of service. Social Behavior and Personality, 35(5), 627-642.

\section{https://doi.org/10.2224/sbp.2007.35.5.627}

Clary, E. G., \& Orenstein, L. (1991). The amount and effectiveness of help: The relationship of motives and abilities to helping behavior. Personality and Social Psychology Bulletin, 171), 58-64. https://doi.org/10.1177/0146167291171009

Clary, E. G., Snyder, M., Ridge, R. D., Copeland, J., Stukas, A. A., Haugen, J., \& Miene, P. (1998). Understanding and assessing the motivations of volunteers: A functional approach. Journal of Personality and Social Psychology, 12(6), 1516-1530. https://doi.org/10.1037//0022$\underline{3514.74 .6 .1516}$ 
Journal of Youth Development | http://jyd.pitt.edu/ | Vol. 15 Issue 4 DOI 10.5195/jyd.2020.881 Volunteer Motivation for Mentoring

Clary, E. G., Snyder, M., Stukas, A. A. (1996). Volunteers' motivations: Findings from a national survey. Nonprofit and Voluntary Sector Quarterly, 24(4), 485-505. https://doi.org/10.1177/0899764096254006

Cnaan, R. A., \& Goldberg-Glen, R. S. (1991). Measuring motivation to volunteer in human services. The Journal of Applied Behavioral Science, 273), 269-284. https://doi.org/10.1177/0021886391273003

Cornelis, I., Van Hiel, A., \& De Cremer, D. (2013). Volunteer work in youth organizations: Predicting distinct aspects of volunteering behavior from self- and other-oriented motives. Journal of Applied Social Psychology, 43(2), 456-466. https://doi.org/10.1111/j.1559-1816.2013.01029.x

Coursey, D., Brudney, J., Littlepage, L., \& Perry, J. (2011). Does public service motivation matter in volunteering domain choices? A test of functional theory. Review of Public Personnel Administration, 31(1), 48-66. https://doi.org/10.1177/0734371X10394405

Davis, M. H., Hall, J. A., \& Meyer, M. (2003). The first year: Influences on the satisfaction, involvement, and persistence of new community volunteers. Personality and Social Psychology Bulletin, 29(2), 248-260. https://doi.org/10.1177/0146167202239050

Dolnicar, S., \& Randle, M. (2007). What motivates which volunteers? Psychographic heterogeneity among volunteers in Australia. VOLUNTAS: International Journal of Voluntary and Nonprofit Organizations, 18(2), 135-155.

Garinger, M., McQuillin, S., \& McDaniel, H. (2017). Examining youth mentoring services across America: Findings from the 2016 national mentoring program survey. MENTOR: The National Mentoring Partnership. https://www.mentoring.org/program-resources/mentor-resources-andpublications/national-survey/

Harris, P. A., Taylor, R., Thielke, R., Payne, J., Gonzalez, N., \& Conde, J. G. (2009). Research electronic data capture (REDCap)-A metadata-driven methodology and workflow process for providing translational research informatics support, Journal of Biomedical Informatics, 42(2), 377-381. https://doi.org/10.1016/j.jbi.2008.08.010

Haski-Leventhal, D. (2009). Altruism and volunteerism: The perceptions of altruism in four disciplines and their impact on the study of volunteerism. Journal for the Theory of Social Behavior, 39(3), 271299. https://doi.org/10.1111/j.1468-5914.2009.00405.x

Hwang, M., Grabb, E., \& Curtis, J. (2005). Why get involved? Reasons for voluntary-association activity among Americans and Canadians. Nonprofit and Voluntary Sector Quarterly, 34(3), 387-403. https://doi.org/10.1177/0899764005276435

Keller, T. E., \& Spencer, R. (2017). Prediction and prevention of premature closures of mentoring relationships: The study to analyze relationships (STAR Project). U.S. Department of Justice, 
Journal of Youth Development | http://jyd.pitt.edu/ | Vol. 15 Issue 4 DOI 10.5195/jyd.2020.881 Volunteer Motivation for Mentoring

Office of Justice Programs' National Criminal Justice Reference Service, (Document No. 251461). https://www.ncjrs.gov/pdffiles1/ojjdp/grants/251463.pdf

Keller, T. E. (2007). Youth mentoring: Theoretical and methodological issues. In T. D. Allen \& L. T. Eby (Eds.), The Blackwell handbook of mentoring: A multiple perspectives approach (pp. 23-47). Blackwell. https://doi.org/10.1111/b.9781405133739.2007.00003.x

Liang, B., Tracy, A., Taylor, C., \& Williams, L. (2002). Mentoring college-age women: A relational approach. American Journal of Community Psychology, 30(2), 271-288. https://doi.org/10.1023/A:1014637112531

Lerner, R. M., Napolitano, C. M., Boyd, M. J., Mueller, M. K., \& Callina, K. S. (2014). Mentoring and positive youth development. In D. L. DuBois \& M. J. Karcher (Eds.), Handbook of youth mentoring (2 ${ }^{\text {nd }}$ ed., pp. 17-27). SAGE. https://doi.org/10.4135/9781412996907.n2

Leyton-Armakan, J., Lawrence, E., Deutsch, N., Williams, J. L., \& Henneberger, A. (2012). Effective youth mentors: The relationship between initial characteristics of college women mentors and mentee satisfaction and outcome. Journal of Community Psychology, 40(8), 906-920. https://doi.org/10.1002/jcop.21491

MENTOR/The National Mentoring Partnership. (2015). Elements of effective practice for mentoring: Research-informed and practitioner-approved best practices for creating and sustaining impactful mentoring relationships and strong program services ( $4^{\text {th }}$ ed.).

http://www.mentoring.org/program-resources/elements-of-effective-practice-for-mentoring/

Newman, D. (2014). Missing data: Five practical guidelines. Organizational Research Methods, 17(4), 372-411. https://doi.org/10.1177/1094428114548590

Omoto, A. M., \& Snyder, M. (1995). Sustained helping without obligation: Motivation, longevity of service, and perceived attitude change among AIDS volunteers. Journal of Personality and Social Psychology, 68(4), 671. https://doi.org/10.1037/0022-3514.68.4.671

Parent, M. (2013). Handling item-level missing data: Simpler is just as good. The Counseling Psychologist, 41(4), 568-600. https://doi.org/10.1177/0011000012445176

Peifer, J., Lawrence, E., Williams, J., \& Leyton-Armakan, J. (2016). The culture of mentoring: Ethnocultural empathy and ethnic identity in mentoring for minority girls. Cultural Diversity \& Ethnic Minority Psychology, 22(3), 440-6. https://doi.org/10.1037/cdp0000078

Raposa, E. B., Dietz, N., \& Rhodes, J. E. (2017). Trends in volunteer mentoring in the United States: Analysis of a decade of census survey data. American Journal of Community Psychology, 1, 1-12. https://doi.org/10.1002/ajcp.12117

Rasoal, C., Eklund, J., \& Hansen, E. M. (2011). Toward a conceptualization of ethnocultural empathy. Journal of Social, Evolutionary, and Cultural Psychology, 5(1), 1. http://dx.doi.org/10.1037/h0099278 
Journal of Youth Development | http://jyd.pitt.edu/ | Vol. 15 Issue 4 DOI 10.5195/jyd.2020.881 Volunteer Motivation for Mentoring

Sánchez, B., Colón-Torres, Y., Feuer, R., Roundfield, K. E., \& Berardi, L. (2014). Race, ethnicity, and culture in mentoring relationships. In D. L. DuBois \& M. J. Karcher (Eds.), Handbook of youth mentoring ( $2^{\text {nd }}$ ed., pp. 145-158). SAGE. https://doi.org/10.4135/9781412976664.n13

Sherman, A., \& Shavit, T. (2012). How the lifecycle explains volunteering during retirement. Ageing and Society, 32(8), 1360-1381. https://doi.org/10.1017/S0144686X11000997

Silverberg, K., Compton, D., \& Coco-Ripp, J. (2003). Motivations of ethnie minorities who volunteer in programs that target under-served youth. World Leisure Journal, 45(3), 53-62. https://doi.org/10.1080/04419057.2003.9674325

Spencer, R., Drew, A. L., Walsh, J., \& Kanchewa, S. A. (2018). Girls (and boys) just want to have fun: A mixed methods study of gender differences in youth mentoring relationship duration. Journal of Primary Prevention, 39(1), 17-35. https://doi.org/10.1007/s10935-017-0494-3

Spencer, R., Basualdo-Delmonico, A., \& Lewis, T. O. (2011). Working to make it work: The role of parents in the youth mentoring process. Journal of Community Psychology, 39(1), 51-59. https://doi.org/10.1002/jcop.20416

Stukas, A. A., Clary, E. G., \& Snyder, M. (2014). Mentor recruitment and retention. In D. L. Dubois, \& M. K. Karcher (Eds.), Handbook of youth mentoring, ( $2^{\text {nd }}$ ed., pp. 397-410). SAGE. https://doi.org/10.4135/9781412996907.n27

Wang, Y., Davidson, M. M., Yakushko, O. F., Savoy, H. B., Tan, J. A., \& Bleier, J. K. (2003). The scale of ethnocultural empathy: Development, validation, and reliability. Journal of Counseling Psychology, 50(2), 221-234. https://doi.org/10.1037/0022-0167.50.2.221 